\title{
Assessing The Public Health Benefits of Parkrun By Modelling Performance And Participation At Events In Scotland
}

Andre Gilburn ( $\sim$ andre.gilburn@stir.ac.uk)

University of Stirling

\section{Research Article}

Keywords: parkrun, fitness, physical activity, participation in sport, inactivity, barriers to participation in sport

Posted Date: November 30th, 2021

DOI: https://doi.org/10.21203/rs.3.rs-1050891/v1

License: (a) (i) This work is licensed under a Creative Commons Attribution 4.0 International License.

Read Full License 


\section{Abstract}

Background: parkrun is a hugely successful public health initiative that encourages inactive people to exercise. The parkrun results database is likely to contain a wealth of potentially important public health information on the fitness benefits and participation patterns of parkrun, yet this resource has been ignored. The aim was to identify patterns in performance and attendance of participants at parkrun events in Scotland to enhance the future health benefits of parkrun through widening participation particularly by identifying features of events that overcome barriers to women taking part.

Study design: The study conducted linear and binomial mixed models of age-graded performance, sex ratio and age of participants at parkrun events held in Scotland. Predictor variables were age, sex, parkrun ID number, number of runs, elevation gain, surface type and travelling time to the next nearest parkrun event. The data were generated from parkrun results pages for 56 events in Scotland.

Results: There was a decline in the mean performance of participants at events, however individual performances improved over time. The sex ratio was male biased but the proportion of female participants has been increasing. Events in the most remote parts of Scotland had the lowest age graded performance scores and the highest proportion of female participants with the remotest events exhibiting a female bias in participation. Events on slower surfaces had a higher proportion of female participants.

Conclusion: This study reports that parkrun events are becoming more inclusive with new participants being increasingly unfit women. In remoter parts of Scotland the traditional male bias in participation in sport has actually become a slight female bias revealing parkrun has seemingly overcome traditional barriers to female participation in sport. Events with slower surfaces had more female participants. Prioritising the creation of events at more remote locations and on slower surfaces could increase inclusivity and widen participation further. These findings could also help general practitioners prescribe those events that are most likely to benefit new participants making the parkrun practice initiative more effective. For example, women might be encouraged to attend traditionally slower events than men.

\section{Background}

The UK has been identified as one of the worst countries in the world for the activity level of its citizens by an international survey of inactivity that found $30-40 \%$ of men and $40-50 \%$ of women in the UK do insufficient physical activity [1]. The gender gap in inactivity in the UK is mirrored by studies in Ireland [2, 3]. Inactivity is a particular problem in Scotland which has the highest level of morbid obesity in the UK [4]. Scotland also hosts the area of the UK with the lowest lifespan with parts of Glasgow having $30 \%$ higher mortality rates than UK average [5]. The level of morbid obesity is predicted in increase dramatically in the UK over the next two decades so this is a worsening problem that requires urgent solutions [4].

One success story that is promoting physical activity is parkrun [6]. Key to parkrun's success is the provision of free $5 \mathrm{k}$ events held at fixed locations every Saturday across more than 20 countries. There is 
no requirement to run, wheelchairs and mobility scooters are welcome, as are buggies and dogs. This helps makes parkrun both more inclusive than traditional sporting events as well as less intimidating to the more inactive. A year-long study of new participants at a UK parkrun event showed an increase in fitness and an associated reduction in body weight [7]. This study also reported increases in perceived happiness and decreases in perceived stress [7]. Many people who did not consider themselves runners have become runners through participation at parkrun events [8]. These people also felt they benefitted the most from parkrun in a survey [8]. Another survey of participants with a mental health issue found they felt that parkrun significantly improved their condition [9]. These studies show parkrun has multifaceted benefits to its participants.

To maximise its impact parkrun UK have launched various initiatives to increase inclusivity and reach the sections of the community that would benefit the most from participating at events. For example, the parkrun practice links parkrun to medical practices in the UK so patients who would benefit from increasing their activity levels are being prescribed parkrun by general practitioners [10]. parkrun have also targeted improving inclusivity via initiatives such as PROVE which aims to get those with long-term health conditions to participate in parkrun [11].

As the number of parkrun events continues to increase parkrun could play an increasingly important role in improving the health of the nation. There are now more than $7005 \mathrm{k}$ parkrun events in the UK and over 2000 worldwide with Scotland hosting 56 weekly 5k parkrun events by the end of 2019. Deprived areas of the UK have been found to have easier access to parkrun events [12]. Despite this participation is still biased towards white, middle-class members of the community with areas with greater density of ethnic minorities and deprived areas exhibiting lower participation levels [13].

Registration for parkrun does not have a gender bias but participation does with females less likely to participate [14]. This suggests there are specific barriers to women participating in parkrun. As women are less active identifying and removing these barriers would help maximise the potential beneficial impact of parkrun events. A study in Tasmania has shown that parkrun can indeed increase participation within those groups least likely to participate in physical activity with social factors being the most important driver of participation [15].

Scotland has some of the most deprived areas of the UK with some of the greatest health problems and levels of morbid obesity $[4,5]$. Scotland also hosts some of the UK's most geographically isolated communities where social factors might result in a very different profile of parkrun participants. Several isolated communities in Scotland now host parkrun events, such as Kirkwall in Orkney, Bressay in Shetland, Thurso in Caithness and Mount Stuart on Bute. The variety in locations of parkrun events in Scotland makes it an excellent potential model system of how well parkrun is impacting fitness levels in different types of communities. Previous studies of parkrun participants and gains in fitness and the benefits of parkrun have been based upon surveys and following small cohorts of volunteers [16]. The one exception was a study of parkrun results using age-graded performance scores [17]. This study showed that age graded scores contain clear patterns in fitness consistent with those found in other 
studies and the parkrun results database is likely to contain a wealth of potentially important information about how to increase the public health benefits of parkrun. The aim of the current study was to conduct the first quantitative assessment of age-graded performance data of all the parkrun events in one area. Scotland exhibits a great variety of parkrun locations and has established problems with obesity making it an ideal model system. In addition, an assessment of participation levels was conducted to determine whether location-based factors affected engagement with parkrun.

\section{Methods}

\section{Data Sources}

Data were collected from the parkrun results pages for all parkrun events in Scotland between 6th December 2008, when the first event took place at Pollok Park in Glasgow, until the 1st January 2020 [18]. The results page for each event was cut and pasted into Excel file and processed using an Excel macro [19]. This extracted information about each participant including their age category, parkrun ID number, sex, age-graded performance percentage, number of participations, date and event. Age is provided in most cases as a five year cohort consequently age was converted to a continuous variable by assigning all participants the mean age for their cohort group. Three additional variables were included that assess various aspects of the different events that could affect performance and attendance. These were elevation gained in metres completing each course, the surface type and the travelling time to the next nearest parkrun in minutes. Elevation gain was determined by plotting the main parkrun route used at each event on Strava routes which provides the number of metres both climbed and descended on a route based upon an elevation database [20]. At most events the start and finish are close together so there is no difference in metres climbed and descended. At events where the start and the finish are separated there was not a substantial difference in elevation with the maximum being $6 \mathrm{~m}$. The mean elevation gained was $43 \mathrm{~m}$ with a range of 0 to $114 \mathrm{~m}$. Using metres descended made no substantive difference to the outcomes of the models and the two variables are too highly correlated to be included in the same model so only elevation gain was used. parkrun events are run on a range of surface types. Hard surfaces such as tarmac and concrete have a relatively low ground contact time and are therefore faster to run on than softer surfaces such as grass and trail paths. The information on surface at each event was taken from the parkrun event course descriptions [18]. Courses run entirely on hard surfaces were assigned a score of 2, those on a mix of hard and softer surfaces a score of 1 and those on entirely softer surfaces a score of 0 . Travelling time between parkrun locations was determined using Google maps between the start location of each pair of events. The data were collected between 8am and 9am on a Saturday morning to get traffic conditions comparable to a parkrun day as events in Scotland start at 9.30, half an hour later than in the rest of the UK. Age-graded performance was used as the measure of how well a parkrunner performed at an event [17]. This is adjusted to consider age and sex and therefore should be directly comparable across all participants [21]. In order to generate registration cohort plots parkrunners were split into parkrun ID cohorts based upon their number with the first group having numbers 1-500000, the second 500001-1000000 etc up to the final cohort of 6500001-7000000. 


\section{Statistical Analysis}

The dataset was analysed in $\mathrm{R} \times 64$ version 4.0.3. All predictor variables were scaled to have a mean of zero and a standard deviation of one. General linear mixed models (package Imer) were used to analyse age and age-graded performance. parkrun ID number was used as a random effect to remove within runner variance. Significance levels were determined using the package Imertest. parkrun ID number was also used as a continuous variable as numbers are allocated in chronological order to investigate variation in the performance of new registrants. A generalised binomial mixed model (package MuMIn) was used to analyse the gender of participants at events with parkrun ID number was again used as a random effect. All figures were generated using ggplot2.

\section{Results}

Is performance at parkrun events in Scotland declining over time?

A linear regression model showed a highly significant decline in performance over time $(F=17960$, d.f. $=$ $1,1572102, \mathrm{P}<0.001$, parameter estimate $=-1.011$, s.e. $=0.008$ ). The mean age graded performance score of participants at Scottish parkrun events has declined year on year from 2008 to 2019 (Fig. 1).

Are more recent registrants getting slower?

A linear regression model showed a highly significant negative association between performance and parkrun ID number $(F=137815$, d.f. $=1,1572102, \mathrm{P}<0.001$, parameter estimate $=-2.937$, s.e. $=0.008)$. When runners are separated into cohorts based upon ID number the continuing decline in performance of new registrants is clear (Fig. 2).

What factors determine age graded performance scores at Scottish parkrun events?

A linear mixed model shows that parkrun ID number is negatively correlated with age graded performance (Table 1). Elevation gain was also strongly negatively correlated with performance. Males performed significantly much better than females. Surface was positively correlated with performance with higher scores being recorded on hard surfaces. The number of parkruns completed and date were also both positively correlated with performance. Age was also significantly associated with performance with older runners performing better. The final significant predictor was the travelling time to the next nearest parkrun with lower performance scores at the most remote parkrun events. There were also three significant interaction terms maintained in the model. Two of these showed that the increases in performance with number of runs and over time were significantly lower in males. The final interaction term was between elevation gained and age with events with more climbing having an increased impact in terms of a reduction in the performance of older runners. 
Table 1

A linear mixed model of performance at Scottish parkrun events. Runner ID was included as a random effect as a factor and as a continuous explanatory variable.

\begin{tabular}{|lllll|}
\hline Parameter & F & P & estimate & S.E. \\
\hline Intercept & & $<0.001$ & 55.310 & 0.032 \\
\hline Runner ID & 9492 & $<0.001$ & -2.029 & -0.021 \\
\hline Elevation gain & 16388 & $<0.001$ & -0.961 & 0.008 \\
\hline Gender (male) & 2894 & $<0.001$ & 1.756 & 0.033 \\
\hline Surface & 1814 & $<0.001$ & 0.352 & 0.008 \\
\hline Runs & 2358 & $<0.001$ & 1.931 & 0.040 \\
\hline Date & 1675 & $<0.001$ & 0.282 & 0.007 \\
\hline Age & 467 & $<0.001$ & 0.478 & 0.021 \\
\hline Travelling time to nearest parkrun & 23 & $<0.001$ & -0.040 & 0.008 \\
\hline Date * gender & 514 & $<0.001$ & -0.136 & 0.006 \\
\hline Runs * gender & 139 & $<0.001$ & -0.446 & 0.038 \\
\hline Gradient * age & 100 & $<0.001$ & -0.074 & 0.007 \\
\hline
\end{tabular}

The sex ratio of participants at parkrun events in Scotland

A generalised binomial mixed model of the sex of participants identified a positive association between age and proportion of males showing an increased bias towards males in older cohorts (Tables 2, Fig. 3). The model also revealed a negative association between proportion of males and parkrun ID showing an increasing proportion of new parkrun participants at Scottish parkrun events are female (Table 2). There was also a negative association with date showing the proportion of male participants is decreasing over time (Table 2, Fig. 4). There was a negative association revealed between the proportion of male participants and how remote a location is showing that females are more likely to participate at more remote events (Table 2, Fig. 5). There was a negative association between the proportion of male participants and elevation gain with females more likely to participate at hillier events. Men were also more likely to attend events on faster surfaces (Table 2). 
Table 2

A generalised binomial mixed model of the proportion of male participants at parkrun events in Scotland. Runner ID was included as a categorical random effect.

\begin{tabular}{|lllll|}
\hline Parameter & Estimate & Standard error & $\boldsymbol{z}$ & $\boldsymbol{P}$ \\
\hline Intercept & 4.222 & 0.064 & 65.00 & $<0.001$ \\
\hline Age & 0.360 & 0.056 & 6.40 & $<0.001$ \\
\hline runnerlD & -5.968 & 0.060 & 99.48 & $<0.001$ \\
\hline Travel time to nearest parkrun & -1.046 & 0.039 & 26.74 & $<0.001$ \\
\hline Surface & 0.802 & 0.042 & 18.98 & $<0.001$ \\
\hline Date & -0.423 & 0.002 & 3710 & $<0.001$ \\
\hline Elevation gain & -0.319 & 0.043 & 7.38 & $<0.001$ \\
\hline
\end{tabular}

An analysis of a subset of the data using only events after 2018 still reveals an association between remoteness and proportion of female runners showing that this finding is not an artefact of remote events being newer and therefore having more female runners. Further analysis of this subset of events reveals that the association between proportion of male participants and age was still present in 2019 as was the finding that a higher proportion of female participants attended events on slower surfaces.

Age of participants at parkrun events in Scotland

A linear mixed model of the age of participants at Scottish parkrun events (Table 3) revealed that the average age is increasing over time (Fig. 6) yet the age of new registrants is decreasing.

Table 3

A linear mixed model of the age of participants at parkrun events in Scotland, Runner ID was included as a categorical random effect and as a continuous predictor.

\begin{tabular}{|lllll|}
\hline Parameter & Estimate & Standard error & $\boldsymbol{t}$ & $\boldsymbol{P}$ \\
\hline Intercept & 36.74 & 0.051 & 714.24 & $<0.001$ \\
\hline Date & 2.321 & 0.002 & 1453.81 & $<0.001$ \\
\hline runnerlD & -2.361 & 0.030 & 79.96 & $<0.001$ \\
\hline Gender (Male) & -0.042 & 0.002 & 2.81 & 0.004 \\
\hline
\end{tabular}

Performance of new participants

A linear model of the performance of the first time each participant took part in a Scottish parkrun event produced a similar set of highly significant associations as identified by the full model (Table 4). The lack of within participant variance means some explanatory variables such as number of participations were 
excluded and only one of runner ID or date were included due to them being highly correlated in this subset of data. A stronger gender effect was detected than in the full model showing that males do particularly well when they first participate compared to females (Table 4). There was a decline in first performance over time (Table 4). A very similar effect is seen with runner ID if this is included instead of date in the model. both cannot be used in the same model as they are too highly correlated. It is also noteworthy that when only participants taking part in their first Scottish parkrun are considered there is also still a decrease in the proportion of male runners over time.

Table 4

A linear mixed model of performance of first timers at Scottish parkrun events. Runner ID was included as a random effect as a factor and as a continuous explanatory variable.

\begin{tabular}{|lllll|}
\hline Parameter & F & P & estimate & S.E. \\
\hline Intercept & & $<0.001$ & 48.170 & 0.059 \\
\hline Gender (male) & 8766 & $<0.001$ & 4.289 & 0.048 \\
\hline Date & 3819 & $<0.001$ & -1.531 & -0.024 \\
\hline Surface & 1972 & $<0.001$ & 0.992 & 0.033 \\
\hline Age & 1439 & $<0.001$ & 0.894 & 0.024 \\
\hline Elevation gain & 424 & $<0.001$ & -0.493 & 0.024 \\
\hline Travelling time to nearest parkrun & 4.95 & 0.26 & -0.070 & 0.023 \\
\hline
\end{tabular}

\section{Discussion}

Factors affecting performance at Scottish parkrun events

This study has identified a range of potentially important patterns in participation and performance at parkrun events in Scotland which could be used to increase the beneficial impact parkrun has on communities both in Scotland and elsewhere. There is a substantial and continuing decline in the average performance of participants at Scottish parkrun events. This is not the result of participants becoming less fit, indeed to the contrary this study identified that individual participants are improving their performance. The decline seems to be occurring as the performance of new participants is declining over time suggesting that parkrun is continuing to become more inclusive and reaching more of the wider community most in need of increasing their level of activity. This is supported by the continuing negative association between parkrun ID number and performance.

These findings are consistent with a smaller scale study of worldwide parkrun results which also found overall performance was declining while individual performance was increasing [17]. This study confirms this finding on a much larger scale. It also identifies several other novel associations within the parkrun results dataset such as better performance on harder surfaces and a reduction in performance with 
increasing elevation gained, particularly in older participants highlighting the potential for this dataset to generate robust findings.

\section{Gender differences in performance}

The study also found a substantial difference in the performance levels of men and women. This fits with the relative patterns of inactivity in the sexes $[2,4]$. The lower level of starting fitness of women is also highlighted by the finding that women improve their performance faster over time and with increasing numbers of completed events than male participants. This shows that women on average benefit more than men from parkrun, something that might potentially be used to encourage more women to participate. It is also noteworthy that the gender gap was significantly wider when only the initial run of each participant was considered showing that men perform a lot better than women on their first run also indicating a higher initial fitness.

The sex differences in performance could be partly explained by greater competitiveness in men but the lack of comparable gains in fitness in men suggests it is more likely that women are comparatively less fit when they join. One reason men might be more competitive could be a higher engagement with the increasing gamification of parkrun. parkrun have received criticism for ranking individual times and maintaining course records [8]. However, these are likely to be important motivatory factors for many to take part so these should be maintained. Furthermore, some elements of the gamification of parkrun are not biased towards those with higher fitness levels such as parkrun tourism through the number of different events attended [22]. Additional gamification of parkrun could be targeted towards the less fit. For example, statistics based upon changes in individual performance. An established athlete beating a parkrun course record is to be admired but an overweight, inactive non-runner becoming an active, lighter, fitter, healthier runner has wider beneficial consequences in terms of the health of the community and its impact on mortality rates and health services. Therefore, promotion of statistics related to improvements in individual performance in addition to ranking absolute performance would be beneficial and could increase participation by those sections of the community who would benefit most. For example, these could include performance score PBs in addition to absolute PBs.

Sex differences in patterns of participation

This study identified several factors associated with the proportion of male participants at events. Those events on faster surfaces and which are closer to other parkrun venues had more male participants. Older participants were more likely to be male, with a female bias in participation occurring in the youngest adults, although there is a significant male bias towards boys amongst juniors. New registrants are more likely to be female, indeed there is a slight female bias in the most recent cohorts of registrants. Despite this it is only the remotest parkrun events that see a female bias in participation. The difference in registration patterns and attendances suggest there might be greater barriers to females attending parkrun events. Remote events could have a greater sense of community identity and as a result feel more welcoming. They might also have a smaller field with fewer elite athletes making them seem less intimidating. The development of strong social identities from being part of the parkrun community has 
been found to be an important component of participation and gaining health benefits from parkrun [22, 23]. If remote parkruns have a stronger social identity then they might be having a disproportionately large impact on the health of the communities they serve. The proportion of female participants was also higher at events run on trails and grass compared to hard surfaces. This could be because these parkruns are at more pleasant locations which could preferentially attract priority groups such as women and those with mental health issues [16]. Tarmac and concrete surfaces might attract more competitive runners and make those events feel less welcoming to the less fit. In Scotland the tarmac and concrete events are also more likely to be in city centre parks with larger numbers of attendees with could also make them feel more intimidating. The strong association between age and the sex of participants suggests that older women are the least likely to take part in parkrun. This could be a result of long-hold social beliefs acting as barriers such as the expectation that women should not participate in sports. It could be fruitful to explore factors associated with relapsing at parkrun for example are older women more likely to relapse after attending a single event? Another barrier to participation in physical activity is the perception that it is potentially dangerous especially for those with long term health conditions, however the evidence suggests that the health benefits of attending parkrun considerably outweigh any risks $[11,25,26]$.

Male participants could also be playing an important role in driving some of the patterns identified by this study. For example, the higher proportion of female participants at events on slower surfaces could be driven by male parkrunners preferentially attending events on faster surfaces. Although male participants selecting events on the basis of their speed could generate biases in sex ratios in areas where there are several events within close proximity this would not be expected to generate the female biases present at remoter events. These would be expected to have average sex ratios not the most female biased which suggests that fewer barriers to female participation are most likely responsible for this finding.

Age of participants at Scottish parkrun events

The average age of participants at parkrun events has started to show a consistent increase despite the average age of those registering for parkrun declining. A key factor in explaining this apparent contradiction could be the establishment of Junior parkrun, shorter $2 \mathrm{~km}$ events for those aged between 414. Junior parkrun events were not included in the study but participants use the same runner ID numbers. This is likely to have encouraged more registrations of children for parkrun. The strong male bias in participation amongst children might suggest than girls find junior parkrun less intimidating than parkrun itself and preferentially attend junior parkrun events. It is also possible that decisions by parents are impacting this trend with parents perhaps more likely to bring boys than girls to $5 \mathrm{k}$ parkrun events.

Implications for parkrun

This study has identified significant patterns in the participation of parkrun events in Scotland. parkrun in Scotland seems to be becoming more inclusive as less fit individuals increasingly take part. The proportion of women taking part has also increased in parallel with this reduction in fitness. Women are particularly willing to take part in the most remote isolated events so these are likely to be having a 
disproportionately large beneficial impact on their local communities. Indeed, remote parkrun events have actually reversed the typical male bias in participation in organised sports by exhibiting a slight female bias in attendance. This suggests that the barriers to women participating present at other events could be absent from remote Scottish parkrun events or alternatively that there are more barriers to male participation. parkrun could try to encourage the creation of events in more remote locations.

Alternatively, it might be the case that people that live in remoter locations are naturally more likely to be active in their local environment. It might be interesting to explore the proportion of the local population who attend these events to determine if it's higher because more women participate or lower because fewer men do as they have other potential options for outdoor pursuits.

The proportion of female participants was also substantially higher at events run on trial paths and grass. parkrun could encourage the creation of softer surface events in areas dominated by hard surface events to provide a less intimidating alternative for female participants which some of the more competitive runners will avoid. Furthermore, the parkrun practice initiative might be increasingly effective if practitioners prescribe not just attendance at a parkrun event but at an event that a new relatively unfit participant will find most welcoming. Finally, an increase in gamification targeted towards improvements in performance could also encourage more participation by those individuals who would benefit the most.

A study of why people stop attending parkrun events would also be useful. For example, are women more likely to relapse after attending a single event? Is this more likely to happen at larger, more urban events with a greater proportion of elite athletes? Understanding what factors are creating barriers to continued participation could be as useful, if not more useful, than studying patterns in participation itself.

\section{Conclusion}

This study has revealed that parkrun is becoming increasing inclusive as evidenced by the continuing reduction in performance of new participants and an increasing proportion of female participants. Individual participants increase their performance revealing fitness benefits of participating in parkrun. Women are known to exhibit greater barriers to engaging in sporting activity. This study reveals that women are more likely to attend remoter events on slower surfaces. Some barriers still remain with fewer women taking part in events in close proximity to other events i.e. those in city centre parks and on faster surfaces suggesting that women might find these events more intimidating. Older women are also still underrepresented in the parkrun community. This study suggests the creating of events on slower surfaces might increase female participation and reveals the importance of remote parkruns to their local communities and how successful they have been at encouraging female participants. These findings suggest that the parkrun practice initiative which currently links specific medical practices to specific parkruns [27] might benefit from more targeted prescriptions to specific types of parkrun events to maximise the chance of continued engagement. It's not over until the fat lady runs.

\section{Declarations}


Ethical approval

Ethical approval was obtained from the Stirling University General University Ethics Committee. All methods were carried out in accordance with relevant guidelines and regulations

Consent for Publication

Not applicable.

Availability of data

The data used for this study are publicly available from the parkrun results pages for each of the events included in the study. For example for Aberdeen parkrun

https://www.parkrun.org.uk/aberdeen/results/eventhistory/

Competing interests

None.

Author's Contributions

This is a single authored paper so all contributions are by that author.

Funding

No funding was received to conduct this study.

Acknowledgements

The author is very grateful to Steve Haake for providing comments on an earlier draft of the manuscript. The author is grateful to Roderick Hoffmann for providing the parkrun results Excel macro and responding rapidly when a minor bug was identified with it. The author acknowledges the use of data owned by parkrun Global and Strava. The data have been accessed as a permitted act for independent non-commercial research purposes through fair dealing legislation allowing access to publicly available databases. Only a small proportion of the parkrun results database was accessed (data from just 56 of more than 2000 events).

\section{References}

1. Guthold R, Stevens GA, Riley LM, Bull FC. Worldwide trends in insufficient physical activity from 2001 to 2016: a pooled analysis of 358 population-based surveys with 1.9 million participants. Lancet Glob Health 2018; 6(10): 1077-86.

2. Lane A, Murphy N, Bauman A. An effort to 'leverage' the effect of participation in a mass event on physical activity. Health Prom Internat 2015; 30: 542-551. 
3. Murphy N, Lane A, Bauman A. Leveraging mass participation events for sustainable health legacy. Leisure Studies 2015; 34: 758-766.

4. Keaver L, Xu BS, Jaccard A, Webber L. Morbid obesity in the UK: A modelling projection study to 2035. Scand J Publ Health 2018; 48(4):422-427.

5. Walsh D, Bendel N, Jones R, Hanlon P. 'It's not 'just deprivation': Why do equally deprived UK cities experience different health outcomes?' Public Health 2010; doi:10.1016/j.puhe.2010.02.006. http://dx.doi.org/10.1016/j.puhe.2010.02.006

6. Haake S. Parkrun: a new model of physical activity for large populations? Sport Exercise Scient 2018; 57:18-19.

7. Stevinson C, Hickson M. Changes in physical activity, weight and wellbeing outcomes among attendees of a weekly mass participation event: a prospective 12-month study. J Publ Health 2019;41(4):807-814.

8. Bowness J, McKendrick J, Tulle E. From non-runner to parkrunner: subjective athletic identity and experience of parkrun. Int Rev Sociol Sport 2020 (6):1-24.

9. Morris $P$, Scott $H$. Not just a run in the park: a qualitative exploration of parkrun and mental health. Adv Mental Health: Promot Prevent Early Intervent 2019; 17 (2): 110-123.

10. Fleming J. parkrun: increasing physical activity in primary care. Br. J. Gen. Pract. 2019; 69 (687): 483.

11. Quirk H, Haake S. How can we get more people with long-term health conditions involved in parkrun? A qualitative study evaluating parkrun's prove project. BMC Sports Sci Med Rehabil 2019;11(1):22.

12. Schneider PP, Smith RA, Bullas AM, Quirk H, Bayley T, Haake SJ , Brennan A, Goyder E. Multiple deprivation and geographic distance to community physical activity events $\mathrm{d}$ achieving equitable access to parkrun in England. Public Health 2020; 189: 48-53.

13. Smith R, Schneider P, Bullas A, Haake S, Quirk H, Cosulich R. Does ethnic density influence community participation in mass participation physical activity events? The case of parkrun in england. Wellcome Open Res 2020;5(9):9.

14. Fullagar S, Petris S, Sargent J, Allen S, Akhtar M, Ozakinci G, Action research with parkrun UK volunteer organizers to develop inclusive strategies. Health Promot Int. 2020; 35: 1199-1209.

15. Cleland V, Nash M, Sharman MJ, Claflin S. Exploring the health-promoting potential of the "parkrun" phenomenon: what factors are associated with higher levels of participation? Am. J. Health Promo. 2019; 33(1): 13-23

16. Grunseit AC, Richards J, Reece L, Bauman A, Merom D. Evidence on the reach and impact of the social physical activity phenomenon parkrun: A scoping review. Prev Med Rep 2020 doi: 10.1016/j.pmedr.2020.101231.

17. Gilburn AS. The Paradox of parkrun: As parkruns Slow, parkrunners Speed Up.

18. ParkrunUK. Parkrun UK website. 2020. Accessed on many dates in 2020]. Available from: https://www.parkrun.org.uk/ 
19. Hoffman R. https://www.facebook.com/groups/parkrunstatsgeeks/files version published October 31 st 2019.

20. https://support.strava.com/hc/en-us/articles/216918387-Routes-on-Web

21. Parkrun support. What is age grading. Accessed on December $15^{\text {th }} 2020$ https://support.parkrun.com/hc/en-us/articles/200565263-What-is-age-grading

22. Sharman MJ, Nash M, Cleland V. Health and broader community benefit of parkrun - An exploratory qualitative study. Health Promot J Austr 2019; 30(2): 163-171.

23. Stevens M, Rees T, Polman R. Social identification, exercise participation, and positive exercise experiences: evidence from parkrun. J. Sports Sci. 2019; 37 (2): 221-228.

24. McKendrick JH, Bowness J, Tulle E. In search of parkrun tourism: destabilising contradictions or progressive conceptual tensions? Intern J Cult Tour Hosp Res. 2020; https://doi.org/10.1108/IJCTHR-10-2019-0183

25. McIntosh T. parkrun: a panacea for health and wellbeing? J. Res. Nurs. 2021; https://doi.org/10.1177/17449871211037327

26. Pedlar CR, Myrissa K, Barry Megan, Khwaja IG, Simpkin AJ, Newell J,Scarrott C,Whyte GP. Kipps C, Baggish AL. Medical encounters at community-based physical activity events (parkrun) in the UK. Brit J Sports Med 2021; 10.1136/bjsports-2021-104256

27. Fleming J, Wellington C, Parsons J, Dale J. Collaboration between primary care and a voluntary, community sector organisation: Practical guidance from the parkrun practice initiative. Health Soc. Care Comm. 2021; DOI:10.1111/hsc.13236

\section{Figures}




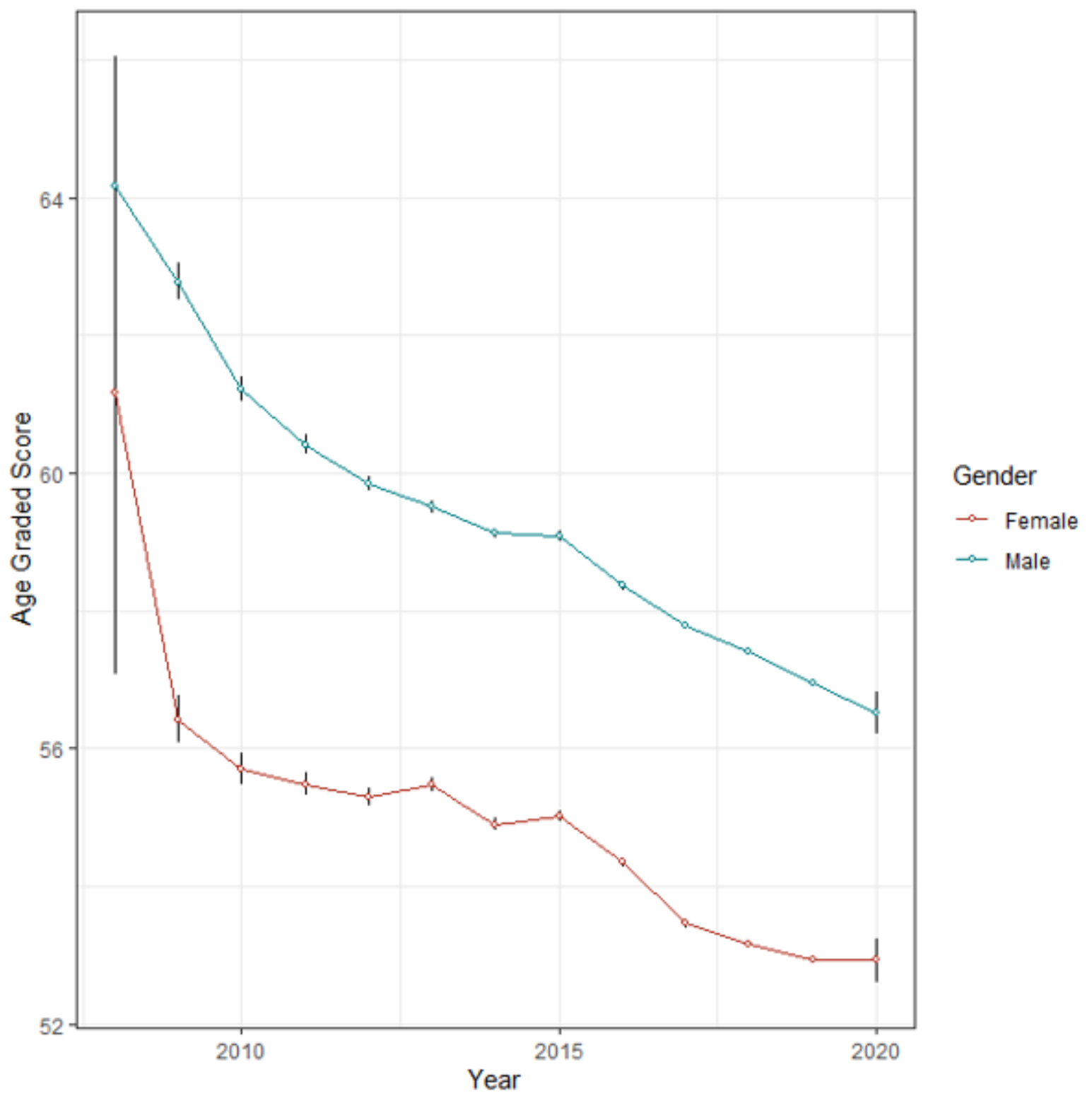

Figure 1

The age graded performance score of male and female participants separated by year at Scottish parkrun events. The error bars are $95 \%$ confidence intervals. 


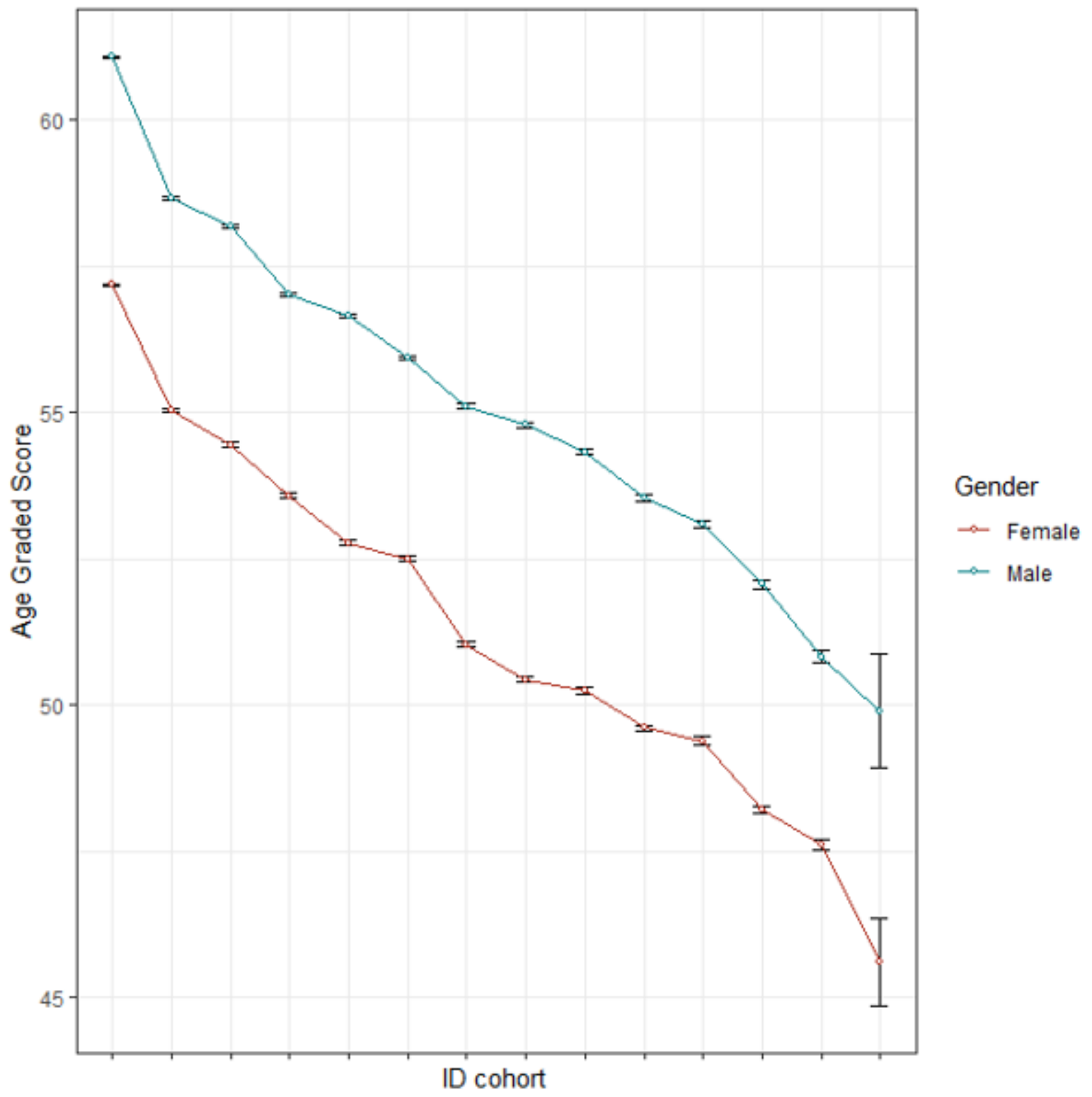

Figure 2

Mean age graded performance score for each ID cohort. Cohorts are separated into groups of 500000 by ID number i.e. ID numbers 1-500000, 500001-1000000 etc so the further to the right of the graph the more recent the cohort of registrants. 


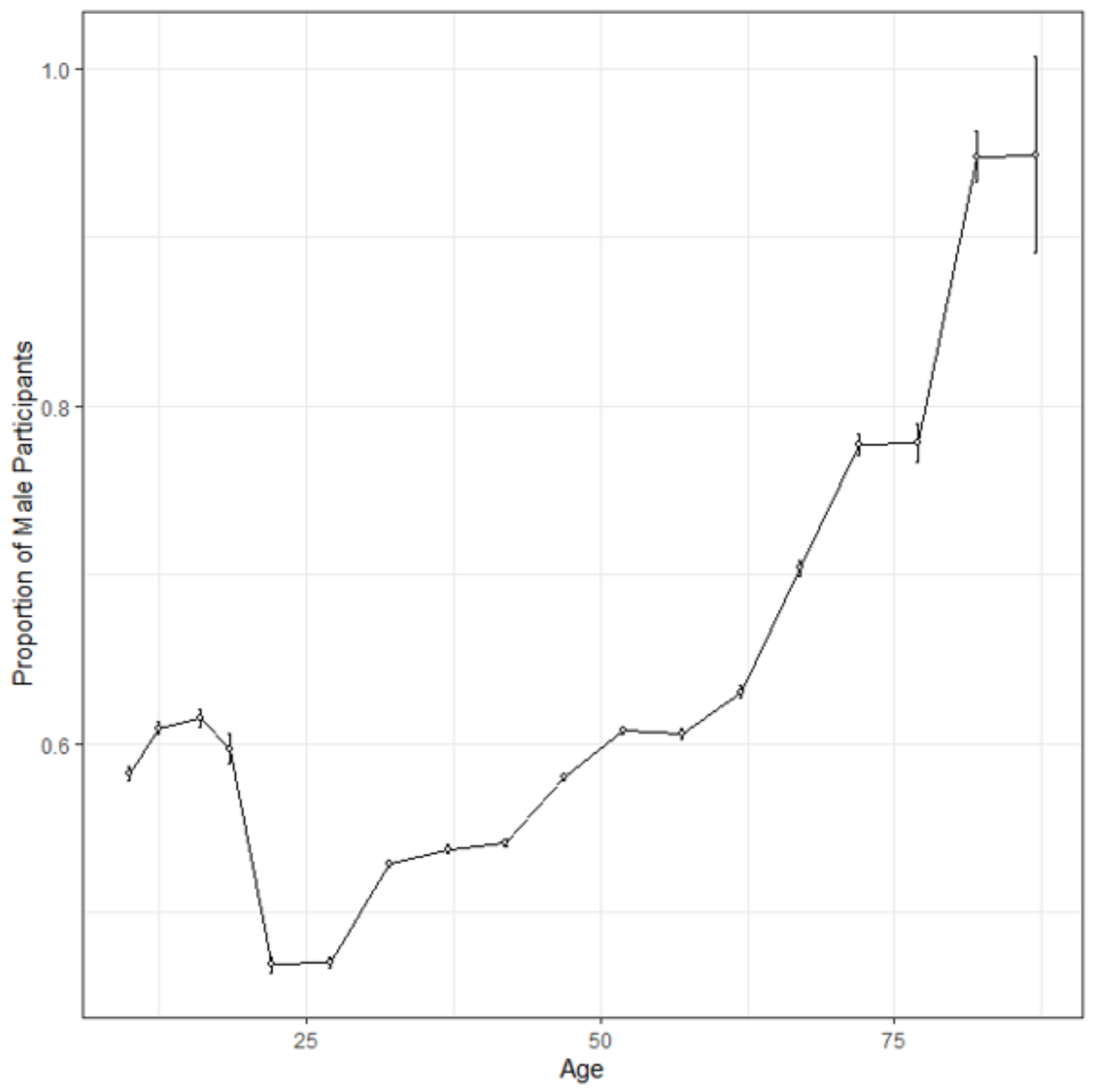

Figure 3

The proportion of male runners in each age cohort at Scottish parkrun events. Error bars represent 95\% confidence intervals. 


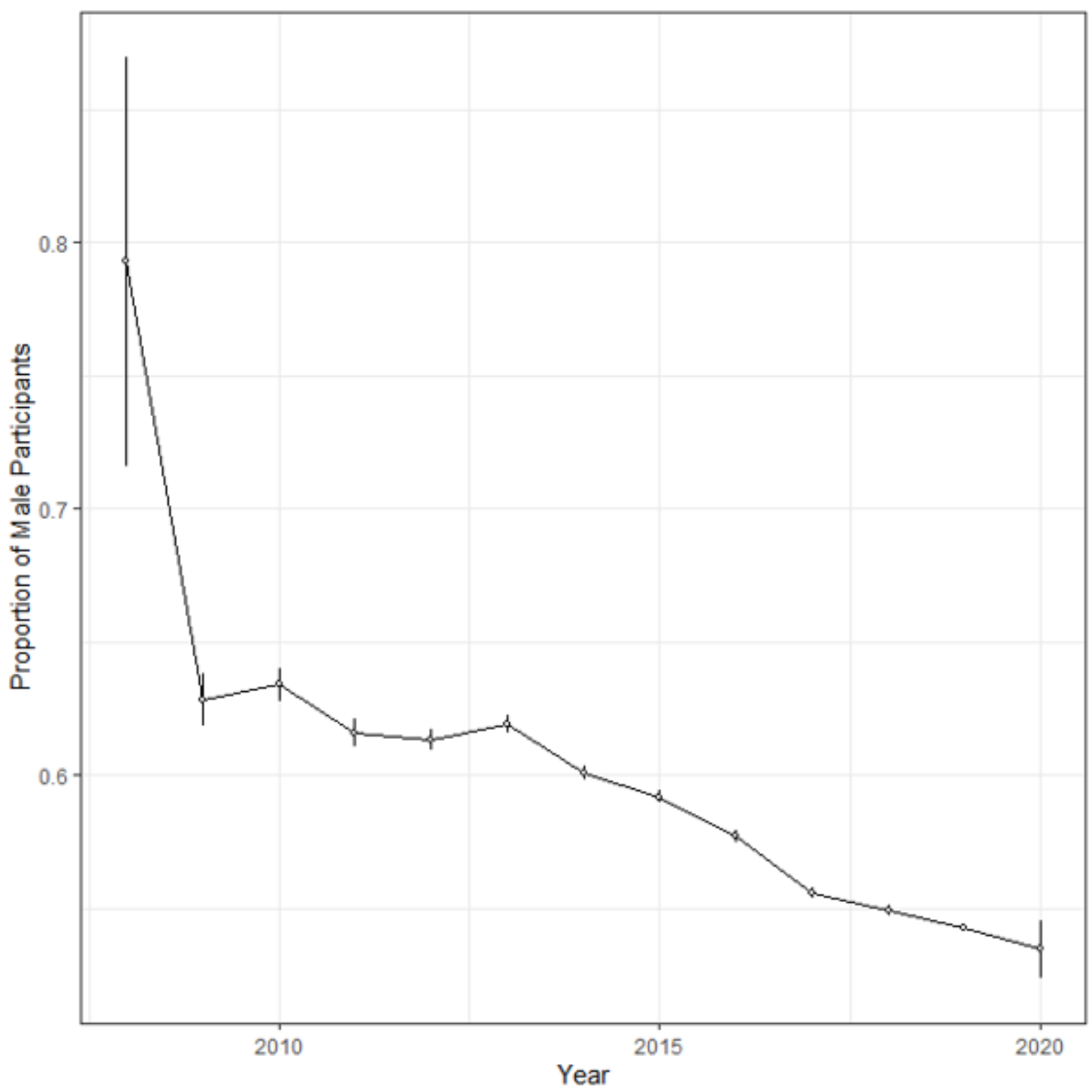

Figure 4

The proportion of male runners by year at Scottish parkrun events. Error bars represent $95 \%$ confidence intervals. 


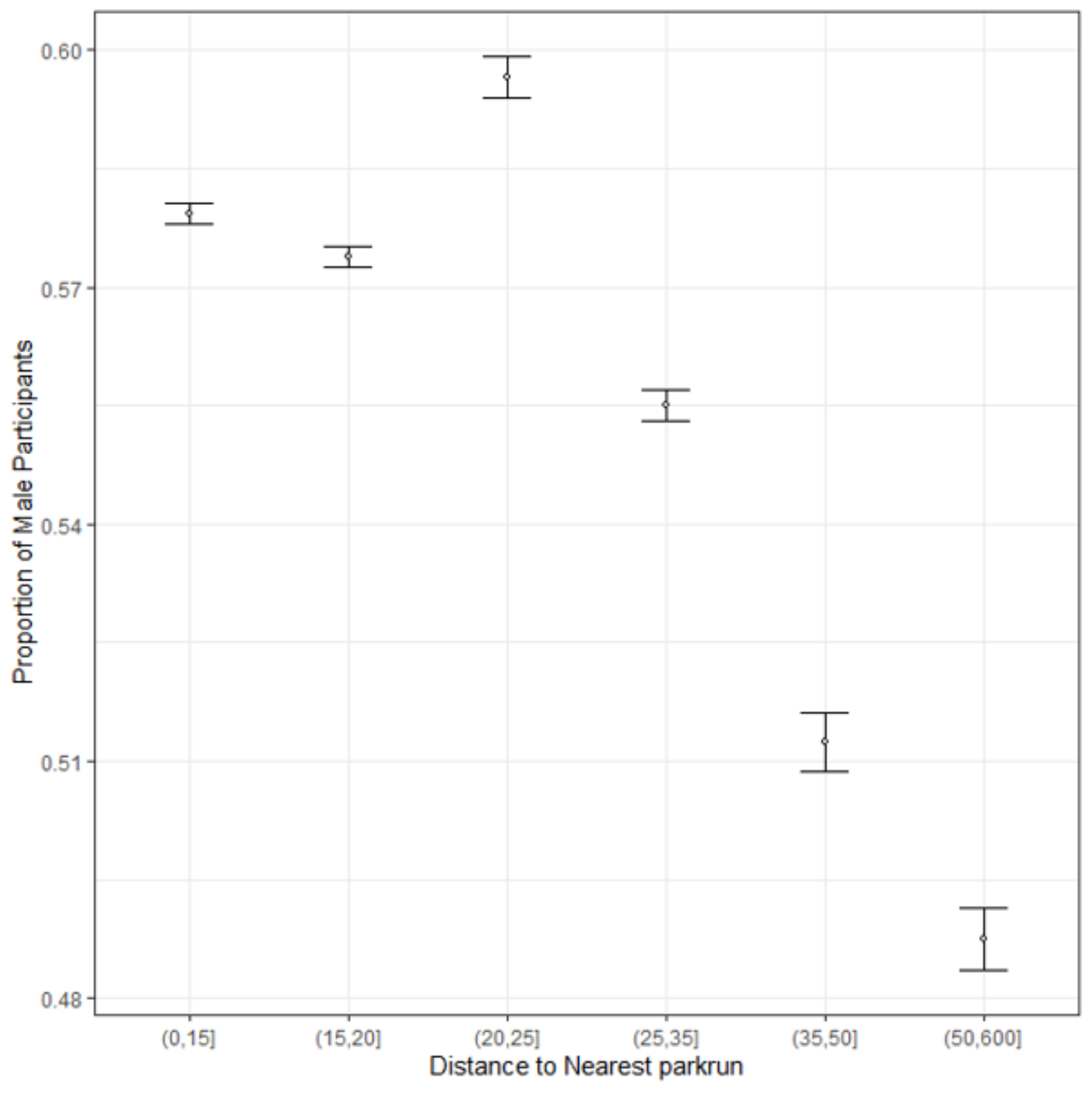

Figure 5

The proportion of male runners by travelling time in minutes to the next nearest parkrun event. Error bars represent $95 \%$ confidence intervals. 


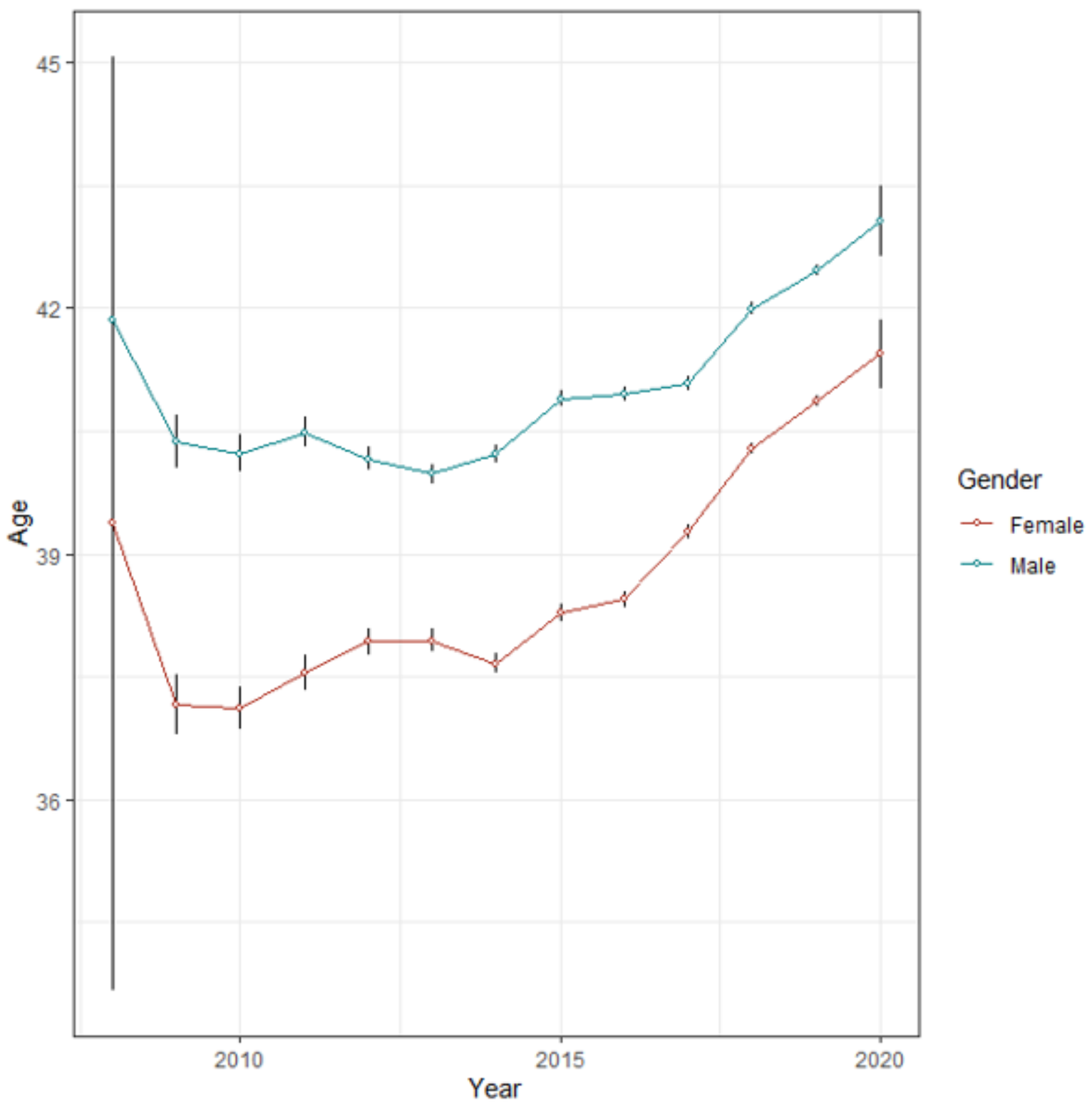

Figure 6

The average age of participants by year at Scottish parkrun events. Error bars represent $95 \%$ confidence intervals. 